\title{
Role of Endothelial Cells in Myocardial Ischemia-Reperfusion Injury
}

\author{
Arun K. Singhal ${ }^{1, \#}$, J. David Symons ${ }^{2, \#, *}$, Sihem Boudina ${ }^{3}$, Bharat Jaishy ${ }^{3}$ and Yan-Ting E. Shiu ${ }^{4}$ \\ ${ }^{I}$ Cardiothoracic Division, Edward J. Hines Veterans Administration Hospital, and Loyola University, Chicago, IL, \\ USA; ${ }^{2}$ College of Health and Division of Endocrinology, Metabolism, and Diabetes, School of Medicine, University of \\ Utah, Salt Lake City, UT, USA; ${ }^{3}$ Division of Endocrinology, Metabolism and Diabetes, and Program in Molecular \\ Medicine, University of Utah School of Medicine, Salt Lake City, UT, USA; ${ }^{4}$ Department of Bioengineering, University \\ of Utah, Salt Lake City, UT, USA
}

\begin{abstract}
Minimizing myocardial ischemia-reperfusion injury has broad clinical implications and is a critical mediator of cardiac surgical outcomes. "Ischemic injury" results from a restriction in blood supply leading to a mismatch between oxygen supply and demand of a sufficient intensity and/or duration that leads to cell necrosis, whereas ischemiareperfusion injury occurs when blood supply is restored after a period of ischemia and is usually associated with apoptosis (i.e. programmed cell death). Compared to vascular endothelial cells, cardiac myocytes are more sensitive to ischemic injury and have received the most attention in preventing myocardial ischemia-reperfusion injury. Many comprehensive reviews exist on various aspects of myocardial ischemia-reperfusion injury. The purpose of this review is to examine the role of vascular endothelial cells in myocardial ischemia-reperfusion injury, and to stimulate further research in this exciting and clinically relevant area. Two specific areas that are addressed include: 1) data suggesting that coronary endothelial cells are critical mediators of myocardial dysfunction after ischemia-reperfusion injury; and 2) the involvement of the mitochondrial permeability transition pore in endothelial cell death as a result of an ischemia-reperfusion insult. Elucidating the cellular signaling pathway(s) that leads to endothelial cell injury and/or death in response to ischemia-reperfusion is a key component to developing clinically applicable strategies that might minimize myocardial ischemia-reperfusion injury.
\end{abstract}

Keywords: Myocardial ischemia-reperfusion injury, endothelial cells, mitochondrial permeability transition pore.

\section{INTRODUCTION}

Myocardial ischemia-reperfusion (IR) injury may result from pathological processes such as atherosclerotic coronary artery disease and acute myocardial infarction and/or be secondary to surgical processes such as operating on the arrested heart or cardiac transplantation. In contrast to "ischemic injury" which occurs when oxygen demand exceeds the available blood supply and is associated with cell necrosis, IR injury occurs upon return of blood supply after a period of ischemia and is usually associated with apoptosis (i.e. programmed cell death). When compared to endothelial cells (ECs), cardiomyocytes (CMs) are more sensitive to ischemic injury and have received the most attention in the quest for preventing myocardial IR injury. However, several studies suggest that ECs are more sensitive to IR injury than CMs and that they might be a critical mediator of IR injury in the heart. This review is focused on defining the critical role of the endothelium in myocardial IR injury.

Cardiovascular disease, the number one killer in the United States, is associated with significant short- and longterm mortality and puts significant economic burden on society. In the United States in 2005, more than 16 million people had symptomatic coronary artery disease (CAD), and

\footnotetext{
*Address correspondence to this author at the College of Health and Division of Endocrinology, Metabolism, and Diabetes, School of Medicine, University of Utah, Salt Lake City, UT, USA; Tel: 801581 4769; Fax: 801 585 0956; E-mail: j.david.symons@hsc.utah.edu

${ }^{*}$ Joint First Authors
}

greater than 1.2 million people are believed to have died from CAD (approximately 1:5.6 deaths). The direct and indirect costs for the care of cardiovascular disease in the United States are estimated to exceed $\$ 400$ billion in 2008. In the most severe case, the 30-day mortality is still approximately $10 \%$. Overall at one year, mortality for myocardial infarction (MI) is between 5 and $13 \%[1,2]$. Understanding the basic mechanism(s) of EC injury/death is critical to developing clinically applicable strategies to minimize myocardial ischemia-reperfusion injury.

ECs do more than provide a protective barrier between the lumen and vascular smooth muscle of blood vessels. These dynamic cells contribute importantly to regulating blood flow, neutrophil, platelet and complement activation, and myocardial function [3-9]. Furthermore, ECs are important in modulating the inflammatory response associated with IR injury, including vascular neogenesis $[10,11]$. Despite the critical role of ECs in myocardial IR injury, most research has focused on the role of CMs [12-14]. As with all pathological processes, avoiding/minimizing exposure to risk factors is optimal. However, should a coronary event occur, early intervention is more effective than attempting to arrest an ongoing process $[11,15]$. With the latter principal in mind, understanding the pivotal role of ECs might lead to the development of more effective therapies that can be applied early in the injury process. The underlying goal of this article is to: (1) review literature on IR induced EC injury and/or death;(2) understand the effects of EC injury on cardiomyo- 
cytes and myocardial function; and (3) discuss potential investigational approaches / strategies.

Ischemia is a process that occurs when the demand for oxygen exceeds the available supply, most commonly as a result of inadequate blood flow. In myocardial infarction (MI), this disruption of flow can result from partial or total occlusion of a large epicardial coronary artery. However, when an occluded vessel is relieved of the blockage, blood flow may not return to pre-occlusion values. In extreme cases, even in the presence of a completely patent vessel, "no-reflow" may occur. "No-reflow" was first described by Kloner in 1974 and was investigated intensely by Menger and Messmer as well as Kloner and colleagues [11, 16-19]. Attenuated flow and / or no-reflow upon reperfusion of an otherwise patent artery might be secondary to a disrupted capillary microcirculation. While many possibilities exist, disruption of the capillary microcirculation distal to the site of occlusion could potentially result from: (1) neutrophil trapping and/or platelet aggregation; (2) myocardial edemaevoked mechanical compression/occlusion of capillaries; and / or (3), swelling and/or damage of ECs in capillaries leading to occlusion of the microcirculation. With regard to the first explanation, while leukocyte and platelet plugging have been demonstrated in vitro, this phenomenon has not been demonstrated in vivo. Furthermore, "no-reflow" occurs in isolated heart models without leukocytes. Concerning the second explanation, complex models of myocyte edema and interstitial pressure do not completely support that model of myocardial swelling $[16,17]$. However, evidence does support a critical role of EC swelling and resultant microcirculatory occlusion in "no-reflow". Specifically, vasodilators such as adenosine, nitroprusside, and verapamil (L-type Ca-channel blocker) are effective at decreasing no-reflow. Additionally, the experimental use of free radical scavengers in isolated striated muscle and heart models is also associated with decreased EC injury and no-reflow [20-22]. Taken together, any and/or all of these proposed explanations could contribute to a greater or lesser extent to attenuated flow / no-reflow that is observed secondary to reperfusion i.e. mechanisms responsible for no-reflow are not precisely known.

"No-reflow" is an extreme example of vascular injury. Intermediate between normal flow and "no-reflow" is reduced flow and decreased vascular reactivity; the latter is the inability of vessels to respond appropriately to an endothelium-dependent and/or -independent vasodilator after an IR insult $[23,24]$. Based on data from isolated vascular ring preparations, arterial relaxation in response to vasodilators such as acetylcholine (an endothelium-dependent vasorelaxing agent) and Nipride (an endothelium-independent vasorelaxing agent) is only mildly decreased following prolonged (four to six hours) periods of ischemia (and no reperfusion) when myocyte damage may precede EC damage [25]. In contrast, much shorter (1.5 hours) periods of ischemia coupled with reperfusion (i.e. IR injury) result in much greater impairment of vascular relaxation $[26,27]$. Thus, reperfusion is an important contributor to IR injury (Table 1).

ECs are more sensitive to IR than to ischemia alone. IR injury is associated not only with immediate vasoconstriction and decreased response to vasodilators at reperfusion but also prolonged vascular dysfunction. In canine infarct models, persistent EC dysfunction can be demonstrated at two but not nine weeks following an IR episode [28]. Although clinical data are more limited, patients suffering from acute MI demonstrate similar vasodilatory dysfunction compared to control patients with chronic atherosclerotic disease. In these patients, early recovery of EC function is associated with improved clinical outcomes [29]. IR injury causes acute and possibly prolonged decreases in vascular function.

Although ECs are less sensitive to ischemic injury, they are quite sensitive to IR injury in the heart [3]. In cell culture, anaerobic glycolytic metabolism can provide adequate energy for ECs [30]. Isolated coronary ECs may catabolize $99 \%$ of glucose into lactate [7]. While the physiological relevance of these cell culture data is unclear, they do provide proof of principle that ECs may be more resistant than CMs to ischemia [30]. Given that ECs can tolerate a relatively wide range of oxygen tensions, they have been proposed as biological oxygen sensors [7, 30-32]. Despite being able to withstand long periods of ischemia, reperfusion evokes a variety of cellular abnormalities that occur quickly. After reperfusion, reactive oxygen species (ROS) production increases, nitric oxide (NO) bioavailability is disrupted, an imbalance of $\mathrm{Ca}^{2+}$ homeostasis occurs, and cells progress to apoptotic death. Each of these will be discussed.

\section{Consequences of EC ROS Formation}

ROS are critical mediators of EC injury. In biological systems, ROS are negatively charged short-lived oxygen species that cause nonspecific and often irreparable oxidative

Table 1. Effects of Ischemia and Reperfusion on Endothelium-Dependent Vasorelaxation (\% Vascular Relaxation) of Isolated Coronary Arteries from Animal Models [25-27]

\begin{tabular}{|c|c|c|}
\hline Ischemic Time & Reperfusion Time & \% Vascular Relaxation Compared to Baseline \\
\hline \hline $1.5 \mathrm{hrs}$ & - & $\approx 85 \%$ \\
\hline $1.5 \mathrm{hrs}$ & $2.5 \mathrm{~min}$ & $16 \pm 6 \%$ \\
\hline $1.5 \mathrm{hrs}$ & $3.0 \mathrm{hrs}$ & $63 \% \pm 6 \%$ \\
\hline $3.0 \mathrm{hrs}$ & - & $32 \pm 4 \%$ \\
\hline $4.5 \mathrm{hrs}$ & - & $31 \pm 6 \%$ \\
\hline $6.0 \mathrm{hrs}$ & - & \\
\hline
\end{tabular}


damage. ROS have been implicated in a host of illnesses such as neurodegenerative diseases (e.g. Parkinson's, Alzheimer's), glaucoma, autoimmune diseases (e.g. scleroderma), cancer, hypertension, renal and vascular diseases [33-37]. Under conditions of prolonged extreme ischemia $\left(\mathrm{FiO}_{2} \leq 1.5-3.0 \%\right)$, increased ROS production occurs in human umbilical vein ECs (HUVECs) and this response can be recapitulated in HUVECs after 90-min of ischemia followed by reoxygenation [38, 39]. Major sources of endothelial ROS production include cytosolic xanthine oxidase and complex I and III of the mitochondrial electron transport chain $[7,31,40]$. Overall the evidence suggests that upon an IR insult, the critical site of ROS production is the mitochondria via the electron transport chain $[30,40]$. The principal ROS produced are $\mathrm{O}_{2}^{-}$(superoxide), $\mathrm{OH}^{-}$(hydroxyl) and $\mathrm{ONOO}^{-}$(peroxynitrite) anions [23]. ROS production occurs rapidly upon reperfusion and is critical in initiating many downstream events. For example, ROS production appears within minutes of reoxygenation in cultured ECs based on electron paramagnetic resonance (EPR) spectroscopy [41]. Given the short half life of free radicals, in vivo data on ROS production are quite limited but ROS formation has been demonstrated in isolated muscle [42] and in rat stroke models [43]. One of the major consequences of ROS production is decreased vasoreactivity [23]. In this regard, ROS production might overwhelm the endogenous antioxidant environment, lower NO bioavailability, and consequently impair endothelium-dependent vasorelaxation. NO, originally known as endothelium derived relaxing factor, is a potent vasodilator $[41,44]$. Therefore, $\mathrm{NO}$ destruction leads to decreased vasoreactivity. Additionally, the production of ROS leads to the expression of surface adhesion molecules $[45,46]$ and complement activation [47], which collectively precipitate neutrophil binding to the EC surface. Once at the site of injury, neutrophils are probably a greater source of ongoing ROS production than ECs. In summary, when ECs produce ROS at reperfusion vasoreactivity is decreased via mechanisms associated with lowered NO bioavailability together with a cascade of inflammatory events that is initiated after surface adhesion molecules are expressed.

\section{Consequences of Reduced NO Bioavailability}

NO is an important modulator of IR injury in experimental models. NO is produced by three NO synthase (NOS) isoforms: inducible NOS (iNOS), endothelial NOS (eNOS) and neuronal NOS (nNOS) [48]. While the primary source of NO in the heart is ECs $[7,24]$, evidence exists that NOS also is located in cardiac ganglion cells and nerve fibers innervating the sinuatrial and atrioventricular nodes, and local neurons, in addition to the myocardium and coronary/pulmonary vessels [49]. Thus, NO is involved in the neural control of heart rate, myocardial cell function, and neuronal transmission in cardiac ganglia, in addition to its vascular dilatory properties [49].

Endogenous basal NO synthesis is low yet an important determinant of regional and systemic vascular resistance. At the onset of ischemia there is an initial increase in the bioavailability of $\mathrm{NO}$ within 5-10 seconds and subsequent vasodilation, but this response tapers within 3-5 minutes [7, $24,48]$. Upon reperfusion NO bioavailability again increases rapidly but wanes within the same time frame as for ische- mia [50]. Evidence that the decrease in NO during sustained ischemia and shortly after reperfusion can be prevented by antioxidants implicates ROS-mediated NO destruction [23, 50]. As NO is short lived, it cannot be delivered directly as a therapeutic agent but rather via NO donors (e.g. Nipride, nitroglycerin) or via increased substrate required for NO synthesis (i.e. arginine). The delivery of these molecules protects from IR injury in the heart via at least two mechanisms [24]. First, NO activates the soluble guanylyl cyclase, which in turn activates a host of cGMP kinases such as protein kinase $\mathrm{G}$, ion channels (e.g. Mito $\mathrm{K}_{\mathrm{ATP}}$ channel) and phosphodiesterases (PDEs) [51, 52]. The end results are vasodilation and decreased platelet adhesion. Second, NO has direct effects on the binding of neutrophils independent of its influence on cGMP activity [48]. Results from mice wherein endogenous NOS inhibition or the eNOS enzyme has been manipulated underscore the importance of $\mathrm{NO}$ bioavailability in contributing to IR injury.

\section{Consequences of Reduced NO Bioavailability : Evidence from Studies of the Endogenous NO Inhibitor Asymmet- rical Dimethylarginine (ADMA)}

Evidence exists that endogenous NO synthase inhibitors contribute importantly to ischemia and reperfusion injury. Reduced bioavailability of NO can result from reduced NO production and/or increased NO degradation. Impaired NO biosynthesis might result from increased levels of asymmetrical dimethylarginine (ADMA). ADMA is an endogenous competitive inhibitor of NOS [53]. ADMA is elevated and closely correlated with impaired vasodilator function [53]. Bae et al. [54] observed increased ADMA concentrations in acute coronary events independent of other cardiovascular risk factors. ADMA is metabolized by the enzyme dimethylarginine-dimethylaminohydrolase (DDAH) [53]. Two isoforms of this enzyme exist; DDAH-1 and DDAH-2. Both isoforms influence NOS function and subsequent endothelial function. Rationale exists for ADMA to influence endothelial function subsequent to IR because systemic administration of other NOS inhibitors either before ischemia or prior to reperfusion increases infarct size, and these effects can be reversed by administering L-arginine [55].

In light of this rationale, Stuhlinger et al. [56] determined whether: 1) ADMA is elevated in response to myocardial IR; 2) ADMA contributes to the severity of reperfusion injury; and 3) DDAH activity/expression modulates tissue ADMA levels and the subsequent damage in response to IR. Coronary artery ligation for 30-min followed by $4 \mathrm{~h}$ reperfusion in hearts from C57B16 mice evoked several well-accepted indices of tissue IR injury. In the same hearts, NOmetabolites were lower and ADMA was higher in tissue obtained at $4 \mathrm{~h}$ of reperfusion vs. 30-min of ischemia. Further, myocardial DDAH was suppressed at $4 \mathrm{~h}$ of reperfusion $v s$. 30 -min of ischemia. These data, together with findings that indices of reperfusion injury (e.g. expression of adhesion molecules, leukocyte distribution and activity, and infarct area) in response to the same IR protocol could be blunted: by L-arginine administration; and in DDAH-1 overexpressing mice, provide solid evidence that the endogenous NOS inhibitor ADMA contributes importantly to IR injury.

Studies from the same laboratory provide evidence that ADMA might have clinical relevance with regard to graft 
coronary artery disease (GCAD) [57]. GCAD is the leading cause of death after the first year of heart transplantation [58]. The authors tested the novel hypothesis that lowering ADMA concentrations by DDAH overexpression in recipient mice might suppress GCAD in cardiac allografts. Donor hearts were heterotopically transplanted into transgenic mice overexpressing DDAH-1. DDAH-1 recipients had lower ADMA, together with indices of reduced oxidant stress, inflammatory cytokines, adhesion molecules, and chemokines. Importantly, indices of GCAD (e.g. luminal narrowing, intima-media ratio, and percentage of diseased vessels) were markedly reduced in DDAH-1 transgenic $v s$. wild type recipients. The authors concluded that protection from GCAD in DDAH-1 overexpressing mice resulted from increased NO bioavailability subsequent to greater metabolism of ADMA in the transgenic animals [57]. Taken together, strategies to reduce levels of ADMA might be therapeutic in GCAD [57] and IR injury [56].

\section{Consequences of Reduced NO Bioavailability: Evidence from eNOS Null Mice}

Cooke et al. provide solid evidence that eNOS is protective regarding myocardial injury subsequent to 30-min ischema followed by $4 \mathrm{~h}$ reperfusion. As such, it is not surprising that IR injury reportedly increased in eNOS-/- mice with deletion of the NADPH ribose and adenine binding sites (i.e. "Harvard eNOS-/- mice" [59]) vs. their WT littermates in response to a similar protocol [60]. However, conflicting evidence exists. For example, Guo et al. reported similar infarct size between Harvard eNOS-/- mice and their WT littermates and mice with deletion of the calmodulin-binding domain [i.e. "University of North Carolina (UNC) eNOS-/mice"] [61] and their WT littermates [62, 63]. Interestingly, protection from IR injury was reported to occur in vivo [60] and in vitro [64] possibly via increased iNOS expression in UNC eNOS-/- mice. Therefore, the contribution from eNOS to IR injury in naïve hearts i.e. no ischemic preconditioning $(\mathrm{PC})$ is equivocal.

PC of the heart refers to the protection afforded by multiple brief ischemic episodes prior to a sustained ischemic insult" $[65,66]$. The protective effects of ischemic PC occur in two distinct phases: an early phase that develops rapidly after the stimulus but dissipates within 2-3 h, and a late phase that becomes apparent 12-24 h later and persists for approximately $72 \mathrm{~h}$ [67-79]. While there appears to be consensus that the late phase of ischemic preconditioning is regulated by eNOS-derived NO $[62,74,80]$, the role of eNOS in early PC is uncertain. For example, studies using pharmacologic inhibition of PI3K, Akt, and / or eNOS have shown evidence that eNOS activation is [81] or is not [8284] an important contributor to the early phase of PC. Recently the PC effect of one or six cycles of 4-min occlusion / 10-min reperfusion prior to 30 -min occlusion $/ 4 \mathrm{~h}$ reperfusion was evaluated in UNC eNOS-/- mice. Because both PC protocols were equally effective at lessening infarct size in UNC eNOS -/- and WT mice, the authors concluded that basal eNOS activity is not necessary for the early phase of ischemic preconditioning in the mouse. Collectively, while the contribution from basal eNOS activity to modulating infarct size in response to IR injury in naïve hearts is equivocal, it appears that basal eNOS activity is not necessary for the cardioprotective effects of the early phase of ischemic PC. This latter conclusion is, however, controversial and warrants further investigation.

\section{Consequences of $\mathrm{Ca}^{2+}$ Imbalance}

$\mathrm{Ca}^{2+}$ homeostasis is important in modulating endothelial cell IR injury. Under physiological conditions, $\mathrm{Ca}^{2+}$ is maintained in a narrow range in both the cytosol and mitochondria $[7,85]$. IR injury is associated with intracellular $\mathrm{Ca}^{2+}$ overload in ECs and CMs, although the mechanisms might be different depending on the cell type [85]. During ischemia, intracellular $\mathrm{Ca}^{2+}$ increases slowly and during reperfusion the $\mathrm{Ca}^{2+}$ increases further. The contribution from $\mathrm{Ca}^{2+}$ overload to IR-induced myocardial dysfunction and coronary vascular dysfunction has been assessed in pigs and rats, respectively[86-89] using the NHE subtype 1 isoform (NHE1) inhibitor 4-isopropyl-3-methylsulfonyl-benzoylguanidine methanesulfonate HOE642 (cariporide, Aventis Pharmaceutical; Frankfurt, Germany]. Cariporide is an inhibitor of the $\mathrm{Na}^{+}-\mathrm{H}^{+}$pump that in turn decreases harmful intracellular $\mathrm{Ca}^{2+}$ overload. In isolated porcine hearts cariporide preserved cardiac function relative to untreated hearts subjected to IR injury. Likewise, IR-induced reductions in systolic wall thickening (sonomicrometry) were delayed and less severe in conscious pigs that were pre-treated with cariporide vs. vehicle [88]. $\mathrm{Ca}^{2+}$ homeostasis may also be involved in vascular dysfunction as pretreatment with cariporide preserves EC function in coronary arteries upon exposure to IR. Specifically, coronary arteries (approx $115 \mu \mathrm{m}$, internal diameter) were obtained from the risk area of rat hearts previously exposed to IR and vascular function was assessed using isometric myography (Fig. 1) [89]. Coronary vasorelaxation to acetylcholine but not sodium nitroprusside was depressed after IR injury, suggesting an IR-induced vascular defect existed that was specific to the endothelium. Specifically, in vessels from rats pre-treated with cariporide and exposed to the same IR protocol, acetylcholine induced vasorelaxation was impaired to a lesser degree [89]. Isolated vessel preparations (e.g. isometric or isobaric myography) are useful to evaluate mechanisms that contribute to endothelial and/or vascular smooth muscle dysfunction because they are independent from neural, humoral, hormonal, and mechanical influences. However, the situation in vivo is not devoid of these influences. Therefore, extrapolation of results using in vitro preparations of arteries obtained from experimental animals to in vivo pathophysiological conditions in humans should be done cautiously. Nevertheless, results from experiments using rats and pigs suggest that NHE1 inhibitors have important therapeutic potential in settings where IR is likely to occur. Furthermore, the benefit likely is conferred upon both CMs and ECs [88, 89].

\section{ENDOTHELIAL AND MYOCARDIAL INJURY}

ECs are uniquely situated to modulate cardiomyocyte function. ECs comprise the inner layer of arteries, veins as well as the endocardial epithelium, and myocardial capillaries. The latter two are critical in regulating cardiomyocyte function $[3,4]$. Although CMs are large cells and represent about $75 \%$ of intracellular cardiac volume, they comprise a minority of the total cell number. In a normal heart, a capil- 
lary is next to almost every CM, and ECs outnumber CMs by approximately $3: 1[3,4]$. Although only a monolayer, ECs, especially in the endocardium, demonstrate a high degree of overlap and interdigitation at cell-cell junctions. Additionally, in the left ventricle of the adult rat, both the intercapillary distance $(\sim 15-20 \mu \mathrm{m})$ and the distance between ECs and myocytes are short $(\sim 1-2 \mu \mathrm{m})[3,4]$. Rather than being just a passive pathway for delivery of blood, nutrients and oxygen to myocytes, ECs have important and unique regulatory functions on myocardial function and can initiate a host response. Each of these will be elaborated upon.
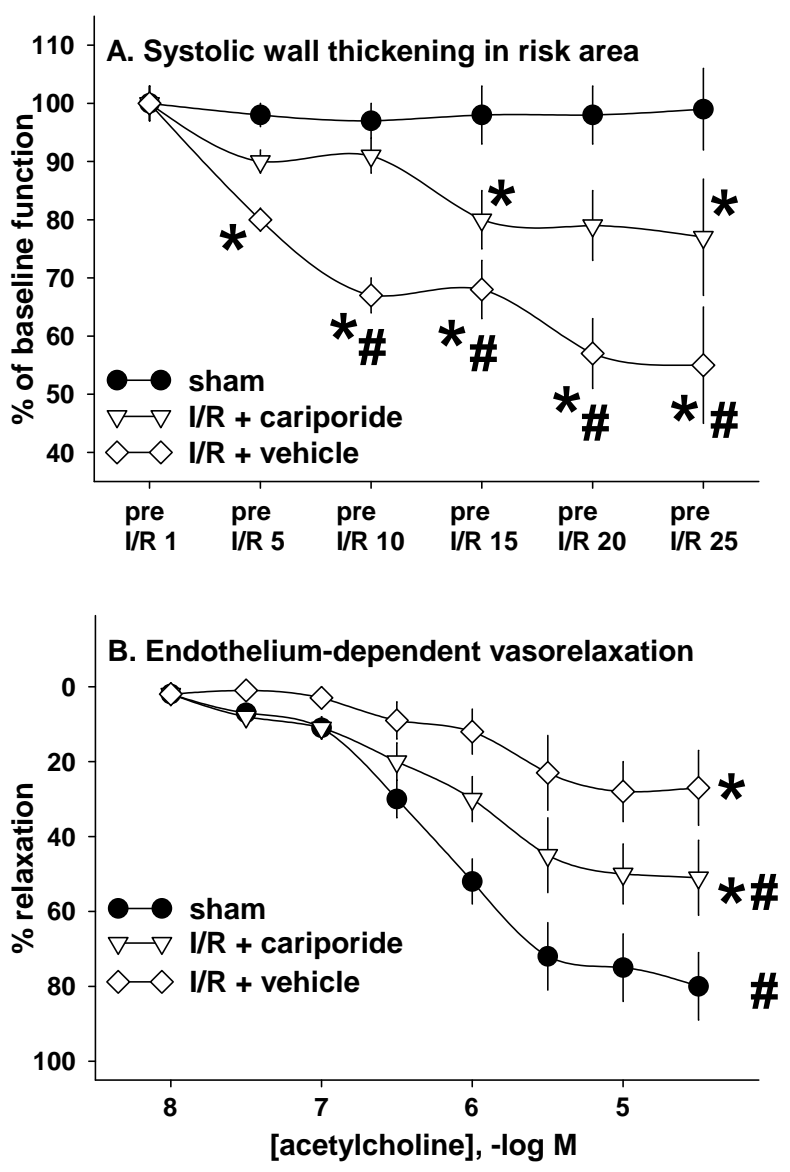

Fig. (1). Panel A. Pretreatment with the sodium-hydrogen exchanger isoform 1 (NHE1) using cariporide attenuates regional dysfunction in response to 25 cycles of ischemia (I, 2-min) and reperfusion $(\mathrm{R}, 8-\mathrm{min})$ of the left circumflex coronary artery $(\mathrm{LCx})$ in conscious swine. Reversible occlusions of the left circumflex coronary artery were performed using a hydraulic occluder. Systolic wall thickening (sonomicrometry) was assessed in the normally perfused (left anterior descending, LAD) and risk (left circumflex coronary artery, LCx) regions. Six animals completed three protocols each separated by one week: 1 ) I/R + VEHICLE (25 I/R cycles + saline infusion); 2) I/R + CARIPORIDE (25 I/R cycles + Cariporide); and 3) SHAM (vehicle administration for 4.2 hours i.e. the occluder was never inflated). Systemic hemodynamics were similar among and within each protocol (data not shown). Blood flow measured during $\mathrm{LCx}$ occlusion (microspheres) confirmed that perfusion was reduced $(\mathrm{p}<0.05)$ in the LCx $v s$. LAD regions. During $\mathrm{I} / \mathrm{R}+\mathrm{VEHICLE}, \mathrm{LCx}$ systolic wall thickening was reduced $\left({ }^{*} \mathrm{p}\right.$
$<0.05$ ) after five IR cycles, and a stable reduction (approximately $55 \%$ of baseline; $\mathrm{p}<0.05$ ) was present after $20 \mathrm{I} / \mathrm{R}$ cycles. During I/R + CARIPORIDE, LCx systolic wall thickening was reduced (*p $<0.05$ ) only after 15 and $25 \mathrm{I} / \mathrm{R}$ cycles (approximately 80 and $72 \%$, respectively). The decrease in systolic wall thickening was greater in I/R + VEHICLE $v s$. I/R + CARIPORIDE $(\# \mathrm{p}<0.05)$. LCx systolic wall thickening was not altered during SHAM, while LAD systolic wall thickening was similar within and among all protocols. These findings indicate NHE1 inhibition delays the onset and limits the degree of regional dysfunction in response to repeated bouts of ischemia and reperfusion. Panel B. Pretreatment with cariporide limits I/R -induced coronary microvascular stunning. Anesthetized rats $(\sim 10$ per group) completed $2 \times 10$-min coronary artery occlusions separated by 5 -min of reperfusion, followed by 15 or $60 \mathrm{~min}$ of reperfusion (I/R). Cariporide or vehicle was administered $15 \mathrm{~min}$ before ischemia (or sham-operation) and was continued throughout each protocol. After reperfusion, hearts were excised, and the reactivity of resistance arteries (internal diameter, $\sim 115 \mu \mathrm{m}$ ) was assessed. The maximal response to acetylcholine-induced relaxation was blunted $\left({ }^{*} \mathrm{p}<0.05\right)$ in $\mathrm{I} / \mathrm{R}+\operatorname{VEHICLE}(\sim 35 \%)$ and $\mathrm{I} / \mathrm{R}+$ CARIPORIDE $(\sim 55 \%)$, compared with sham-operated animals $(\sim 85 \%)$. However, the percent relaxation to acetylcholine was greater $(\# \mathrm{p}<0.05)$ in vessels from I/R + CARIPORIDE and SHAMoperated rats vs. I/R + VEHICLE animals. Relaxation to sodium nitroprusside was not different among groups (data not shown). Results were similar in vessels obtained from animals after $60 \mathrm{~min}$ or 15-min of reperfusion. These findings indicate NHE1 inhibition before coronary occlusion lessens ischemia-induced microvascular dysfunction for 15-60 min after reperfusion. This figure is reprinted with permission from the American Physiological Society (APS) from " $\mathrm{Na}+\mathrm{H}+$ exchange subtype 1 inhibition reduces endothelial dysfunction in vessels from stunned myocardium" Am J Physiol Heart Circ Physiol 2001 281: H1575-H1582, APS identifier H925$0]$.

\section{The Endothelium has Important Regulatory Functions on the Myocardium}

ECs modulate CM growth, metabolism, contractility, apoptosis and arrythmogenicity by synthesizing and releasing a variety of signaling molecules. In addition to its vasodilatory effects, NO functions as a signaling molecule. Although NO has a very short half life, because of the close proximity between ECs and CMs, NO is able to diffuse to $\mathrm{CMs}$ and regulate contractility, electrical activity, and oxygen consumption of CMs [3]. Other EC signaling molecules include factors responsible for vasoregulation (e.g. prostacyclin, endothelin-1, and angiotensin II,), inflammation (e.g. IL-1, TNF-alpha), and growth [e.g. vascular endothelial growth factor (VEGF), and platelet derived growth factor (PDGF)]. Major signaling molecules associated with ECs are outlined in Table 2.

\section{EC Injury Correlates with Myocardial Injury}

We and others have demonstrated in an isolated heart model that immediately following an IR insult, vascular function strongly correlates with cardiac function $[86,98$, 99]. In isolated rat hearts pretreated with verapamil prior to subjecting the organs to 30 minutes of no flow, preservation of coronary flow was significantly correlated with functional recovery (Fig. 2). These improvements were associated with 
decreases in histopathological markers (NF-kB translocation and apoptosis) in EC [98]. In both treated and untreated hearts, minimal cardiomyocyte damage was noted. Although the actual mechanism(s) whereby preserved endothelial function leads to cardioprotection is unclear, hypotheses include enhanced microcirculation, decreased capillary permeability and interstitial edema [99]. In summary, IR injury is associated with decreased vasodilation, which in turn correlates with decreased myocardial function.

Table 2. Signaling Molecules Associated with Endothelial Cells and their Effects

\begin{tabular}{|c|l|}
\hline Modulator & \multicolumn{1}{|c|}{ Effect Related to IR } \\
\hline \hline NO & $\begin{array}{l}\text { Myocardial contractility (Negative inotrope) [24, 90] } \\
\text { Arrhythmias [91] } \\
\text { Decreased Myocardial Oxygen Consumption [92] }\end{array}$ \\
\hline Prostacyclins & Prevent Oxidative Damage [93] \\
\hline Endothelin-1 & Cardiomyocyte hypertrophy/apoptosis [94] \\
\hline $\begin{array}{c}\text { IL-1 and TNF- } \\
\text { alpha }\end{array}$ & Chemo attractant for neutrophils [95] \\
\hline VEGF & $\begin{array}{l}\text { Prevent cardiomyocyte apoptosis [96] } \\
\text { Decreases endothelial permeability [97] }\end{array}$ \\
\hline PDGF & Prevent cardiomyocyte apoptosis [95, 98] \\
\hline
\end{tabular}

\section{Injured Endothelium Initiates Host Response}

Neutrophils, platelets and plasma proteins modulate the extent of myocardial injury and inflammation after an IR event. ECs are critical in activating these blood elements. Normally ECs form a barrier against inflammation by preventing neutrophil and platelet activation. Injury upregulates the expression of multiple surface proteins on ECs that lead to binding of leukocytes, platelets, and plasma proteins to the EC surface; this in turn leads to inflammation and further damage. The role of neutrophils, platelets and plasma proteins in IR injury has been detailed elsewhere [10, 100]. This article focuses on the role of ECs in activation of these various effectors.

The EC surface proteins that are associated with IR injury are known as selectins and immunoglobulin cell adhesion molecules (CAM), which have different time courses of activation and expression (Table 3 ). The earliest adhesion molecule expressed is P-selectin, which is constitutively expressed and stored in Weibel-Palade bodies located in the cytosol, and translocated to the EC surface within seconds or minutes of reperfusion [24]. P-selectin is responsible for initial leukocyte binding on the endothelial surface. In an in vivo feline infarct model, the infusion of anti-P-selectin antibody prior to reperfusion reduces infarct size by approximately 50\% [101]. Additionally, in vitro, anti-P-selectin antibody treatment preserved endothelial response to acetylcholine, $\mathrm{NaNO}_{2}$, and other vasodilators [102]. Lastly, anti-Pselectin antibody treatment was shown to decrease neutrophil binding to ECs ex vivo. In a recent study, delivery of anti-Pselectin antibody via the coronary sinus resulted in a significant reduction in infarct size [103]. ICAM-1, a member of the CAM superfamily is expressed on ECs four to six hours after reperfusion. Both P-selectin and ICAM-1 are associated with leukocyte activation, but ICAM-1 may be more important than P-selectin in initiating the migration of leukocytes across the endothelium and into the myocardium. As with the anti-P-selectin antibody treatment, anti-ICAM-antibody treatment prior to the onset of reperfusion reduced infarct size, preserved vasodilatory response in isolated coronary rings, and decreased binding of leukocytes in a feline infarct model [104]. Similar beneficial effects have also been found in a rat infarct model [103]. However, at present no supporting data are available from human clinical trials for either anti-P-selectin or anti-ICAM-1 antibodies in treatment of myocardial ischemia and reperfusion.
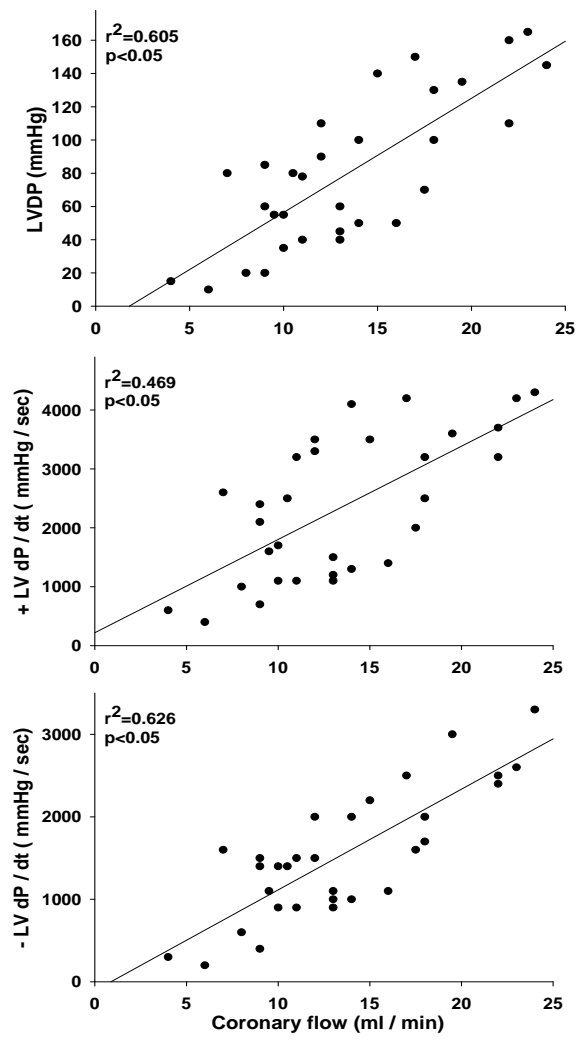

Fig. (2). Correlation between cardiac function and coronary flow. Isolated hearts were perfused at $80 \mathrm{mmHg}$ for 30 -min with KrebsHenseleit buffer at $37{ }^{\circ} \mathrm{C}$. Next, hearts completed 30-min of noflow ischemia followed by $60-\mathrm{min}$ reperfusion. Cardiac functional measurements were obtained immediately at the end of reperfusion. Left ventricular (LV) developed pressure (LVDP, $\mathrm{mmHg}$ ), and positive and negative (-) $\mathrm{LV} \mathrm{dP} / \mathrm{dt}(\mathrm{mm} \mathrm{Hg} / \mathrm{sec})$ correlated significantly with coronary flow [98].

Although less well studied, ECs are important activators of platelets and plasma proteins. Similar to leukocytes, platelets bind to a variety of EC surface receptors including Pand E-selectin, glycoproteins, and the fibronectin receptor. Platelet activation in turn can lead to further upregulation of both selectins and ICAM through the release of proinflammatory proteins from platelet granules. Normally ECs are the only natural anti-thrombogenic barrier. Platelets are strongly attracted to and activated by the underlying subendothelial structural molecules including collagen and Von Willebrand factor. Similarly, activated complement complex, 
C5b-C9 - the membrane attack complex, is found early after reperfusion on the EC surface [105]. The rapid activation of complement in injured human umbilical vein endothelial cells (HUVECs) appears to occur through the activation of the classical pathway by activation of $\mathrm{C} 3$ and possibly by direct activation of C5 due to increased free radicals [106]. CD46 and CD55 are EC surface receptors that are protective from $\mathrm{C} 3$ activation, and they appear to decrease after IR injury in vitro [107]. In turn, both platelets and complement appear to be important in further activating leukocytes. In summary, strong evidence exists that EC surface proteins activate leukocytes, platelets and complement, which in turn might contribute importantly to the severity of IR injury.

Table 3. Endothelial Cell Surface Receptors and Activation of Leukocytes, Platelets, and Complement

\begin{tabular}{|c|c|}
\hline Blood Element & Endothelial Cell Surface Receptors/Activator \\
\hline \hline \multirow{3}{*}{ Leukocytes } & P-selectin \\
& E-selectin \\
& ICAM \\
& PECAM \\
Platelets & P-selectin \\
& E-selectin \\
& Vibronectin receptor \\
Complement & Glycoproteins \\
\hline
\end{tabular}

\section{POTENTIAL THERAPEUTIC APPROACHES}

Recently, the reperfusion injury signaling kinase (RISK) pathway, has been ascribed as a putative common pathway whose activation may be protective from IR injury [14, 108]. The RISK pathway involves multiple parallel signaling pathways and is a good framework for understanding the pathophysiology of IR induced cardiac injury and developing novel therapeutic approaches (See Fig. 3). The RISK pathway has been extensively studied in both CMs and hepatocytes, but we believe that the findings might be just as relevant in ECs [14, 109, 110]. The central components of the pathway are phosphatidylinositol 3-kinase (PI3K), protein kinase B (Akt) and p42/p44 extra-cellular signal-regulated kinases (Erk 1/2) [14, 108]. Phosphorylation of PI3K-Akt activates multiple downstream substrates: glycogen synthase kinase-3, apoptotic proteins (BAD, BAX, p53 and caspases), eNOS and PKC. Akt kinase specifically appears to be critical in IR induced injury. Erk 1/2 are among a family of serinethreonine kinases that control cell proliferation and survival. The final and irreversible step in IR-induced cell death is the mitochondrial permeability transition pore (MPTP) opening $[108,111]$. Below we will further expand on this pathway and the commonality of three potential approaches to the prevention of IR injury: (1) pharmacological (pre)treatment, (2) preconditioning and (3) postconditioning in terms of activating the RISK pathway.

\section{RISK Pathway in EC}

The RISK pathway is critical in reducing whole heart and EC IR injury. Support for this statement is provided by two studies. First, isolated rabbit hearts were subjected to 30-min of regional ischemia and 2 hours of reperfusion with and without pretreatment with insulin, a global activator of PI3K [112]. Infarct size was determined by triphenyltetrazolium staining and expressed as a percentage of the area at risk. Second, isolated perfused mouse hearts completed 35-min of global ischemia and were reperfused for $30 \mathrm{~min}$ with and without pretreatment with atorvastatin, an EC specific activator of PI3K [113, 114]. Despite difficulties in comparing results from experiments using different species, the similarity of protection afforded by atorvastatin and insulin is quite remarkable (see Table 4).

Table 4. Effect of Treatment (Atorvastatin or Insulin) \pm Wortmannin on Infarct Size (Expressed as a Percent of Area at Risk) in Isolated Heart Preparations

\begin{tabular}{|c|c|c|c|}
\hline \multirow{2}{*}{ Treatment } & \multicolumn{3}{|c|}{ Infarct Size } \\
\cline { 2 - 4 } & Control & Treatment & $\begin{array}{c}\text { Treatment }+ \\
\text { Wortmannin }\end{array}$ \\
\hline \hline Statin (mouse) & $33 \pm 2$ & $16 \pm 2$ & $31 \pm 2$ \\
\hline Insulin (rabbit) & $32 \pm 2.3$ & $14.7 \pm 2.1$ & $28.3 \pm 2.2$ \\
\hline
\end{tabular}

Postconditioning also is protective from IR injury via PI3K-Akt activation. Postconditioning induces shear stress in EC which can precipitate Akt activation [90, 115-117]. In a series of preconditioning experiments in human brain microvascular endothelial cells, activation of PI3-kinase/Akt was necessary to protect endothelium from apoptotic cell death [116]. Causal evidence for the RISK pathway in preconditioning was demonstrated by the PI3-kinase inhibitor LY-294002. PI3K inhibition prevented Akt phosphorylation and reversed the protective effects of preconditioning. Similarly, the red wine antioxidant Resveratrol, a known activator of Akt, in part generates its protective effects on the endothelium [118]. In summary, the RISK pathway is a common pathway that is protective not only in cardiomyocytes but also in ECs of which further detail will be provided below.

\section{Insulin, RISK Pathway and Myocardial Injury}

Insulin regulates cardiac metabolism and is an upstream regulator of the RISK pathway. As such, insulin represents an important pharmacological approach and is an excellent tool for understanding the RISK pathway. For example, when insulin receptors are absent in CMs glucose oxidation and fatty acid oxidation are altered such that cardiac function is attenuated $[119,120]$. When insulin binds to its receptor a complex signal transduction network is activated that regulates numerous cellular functions [121, 122]. The activated insulin receptor is trans-autophosphorylated on multiple tyrosine residues in its cytosolic domain. The activated insulin receptor recruits and phosphorylates insulin receptor substrate (IRS) proteins. IRS phosphorylation leads in turn to its binding to the p85 regulatory subunit of PI3K [123] which then activates the catalytic subunit p110 to generate phosphoinositol 3,4,5 triphosphate (PIP3). The latter recruits 3phosphoinositide-dependent protein kinase-1 (PDK-1), which results in its activation. Activated PDK-1 phosphorylates and activates downstream targets such as Akt and phosphokinase $\mathrm{C}$ (PKC). In addition to PI3K-dependent insulin 
signaling, another downstream limb involves IRS-1 activation of small GTPase Ras, which then activates Raf kinase, the MAP kinase (MKK1) and ERK 1/2. PI3K, Akt and ERK1/2 are part of the RISK pathway.

Insulin receptors are expressed in CMs and in a variety of other cells in the heart including ECs. Indeed insulin receptors are expressed in ECs of both large and small blood vessels [124, 125]. In ECs, the PI3K/AKT pathway mediates an anti-apoptotic effect and also results in an increase in gene expression and activation of eNOS [120, 125-127]. Insulin has been suggested to act on the endothelium to produce potential mediators of hormone action, such as NO and cGMP [125, 128, 129]. Knockouts of the insulin receptors in ECs have altered ET-1 and eNOS expression.

No flow ischemia was shown to inhibit insulin signaling via the reduction of intracellular $\mathrm{pH}$ [130]. Insulin and insulin like growth factors (IGF) protect hearts from IR injury $[131,132]$. These effects are mediated via activation of PI3K. In parallel, Akt activation has been shown to prevent injury after transient cardiac ischemia in vivo [133]. In contrast, chronic activation of Akt was deleterious to the heart during the onset of ischemia in an ex-vivo mouse model. In this study, over-expression of an activated form of Akt prevented hearts from recovery after ischemia. However, restoration of $\mathrm{PI} 3 \mathrm{~K}$ reduced ischemic injury in Akt transgenic hearts [134]. It is unclear how activation of insulin signaling, whether prior to ischemia or at reperfusion, limits damage caused by ischemia. It has been proposed that, the activation of Akt is pro-survival and can limit cell death [131, 133]. The latter study also proposed that activation of Akt increases glucose transport after ischemic injury to the same level seen with insulin stimulation. Further, insulin was shown to phosphorylate a proapoptotic molecule which in turn limits cell death [132].

An extensive work has been conducted to understand the downstream targets of insulin-mediated cardioprotection. Baines and coworkers have shown that insulin mimics the cardioprotection afforded by ischemic PC (discussed above and below) and that both insulin treatment and ischemic PC involve PI3K activation [112]. However, insulin-mediated cardioprotection is independent of activation of both PKC and mitochondrial ATP-sensitive channel [112]. The cascade initiated by ischemic PC-activation of PI3K required PDK1, because hearts from PDK1 hypomorphic mutant mice could not be preconditioned. The signaling pathway involving PDK1 converges to AKT and glycogen synthase kinase $3 \beta$ (GSK3 $\beta$ ) activation and a consequent change in mitochondrial membrane potential [135]. There is increasing evidence that mitochondria-mediated death pathway occurs in the heart as a result of IR injury [136-138]. The MPTP plays a central role in this process [139]. Insulin signaling has been postulated to modulate the MPTP opening. Indeed, insulinmediated GSK3 $\beta$ inhibition is involved. The exact mechanism by which inhibition of GSK3$\beta$ modulates insulin mediated-MPTP function is still unknown.

\section{Role of MPTP in Endothelial Cell Injury}

As noted the final step is MPTP opening. The MPTP consists of three proteins, adenine nucleotide translocator (ANT), voltage dependent anion conductance (VDAC) and cyclophilin D (CyD) that span the inner and outer mitochondrial membranes and have a pore size of 1500 Da (Fig. 4). ANT spans the inner membrane and is primarily responsive to the ligands ADP, ATP and dADP, and translocates ADP into and ATP out of the mitochondria. VDAC spans the outer mitochondrial membrane and appears to have a role in transporting metabolites. CyD appears to have an important regulatory role in pore opening and confers cyclosporine (CSA) sensitivity. During steady state conditions the MPTP is closed and allows the maintenance of a mitochondrial membrane potential that generates ATP via oxidative phosphorylation. CSA is an important tool in understanding the role of MPTP IR injury. For example when CSA binds to CyD MPTP pore opening is prevented and IR injury is minimized [137, 140]. Mice lacking CyD are more resistant than wild type mice to IR injury [141, 142]. MPTP appears to be critical in cell death from $\mathrm{Ca}^{2+}$, oxidative stress and ischemia but not radiation [141].

The MPTP is a nonspecific pore whose opening is associated with cell death whether necrotic or apoptotic [12, 32, 109, 136, 143-145]. Initiation of MPTP opening may occur through an "extrinsic" or ligand mediated activation of a death receptor or through an "intrinsic" pathway. The "extrinsic" pathway is mediated by tumor necrosis factor- $\alpha$ or FAS to cell surface receptors [12]. The intrinsic pathway is mediated by imbalances in cellular metabolism such as increased ROS, acidosis, and increased intracellular $\mathrm{Ca}^{2+}$ all of which have been discussed above. The severity of damage is dependent on the duration of MPTP opening and the number of mitochondria involved. For example, the MPTP may: 1) open briefly or flicker resulting in no loss of mitochondrial membrane potential; 2) open longer but then close leading to apoptosis via release of apoptotic factors discussed below; or 3 ) open and remain open resulting in loss of mitochondrial membrane potential and eventually necrosis. Overall, the severity of damage is dependent on the duration of MPTP opening and the number of mitochondria involved. Major consequences of MPTP opening are loss of mitochondrial membrane potential and release of apoptotic factors (Table 5). Of the apoptotic factors released as a consequence of MPTP opening, Cytochrome $\mathrm{C}$ may be the most important leading to activation of Caspase 9 , and a consequent destruction cascade beginning with activation of Caspase 3 . In addition to release of proapoptotic factors and loss of the mitochondrial membrane potential, other deleterious consequences of MPTP opening include depletion of ATP, elevation of mitochondrial $\mathrm{Ca}^{2+}$, and increased mitochondrial ROS formation. The end result is cell death and loss of oxidative phosphorylation.

\section{Pharmacological Pretreatment}

Drug treatment is often protective when administered prior to ischemia $[86,88,89,98,99,111,147-154]$. These drugs include insulin, adenosine and adenosine agonists, bradykinin, statins, cariporide, cyclosporine (CSA), and sanglifehrin A (SFA). All except for CSA and SFA likely work upstream from MPTP opening. In contrast, CSA and SFA directly regulate the MPTP. None of these, except for insulin, has been tested clinically $[152,153]$. In summary, in vitro and in vivo models demonstrate that pharmacological treatment can be protective from IR injury. 


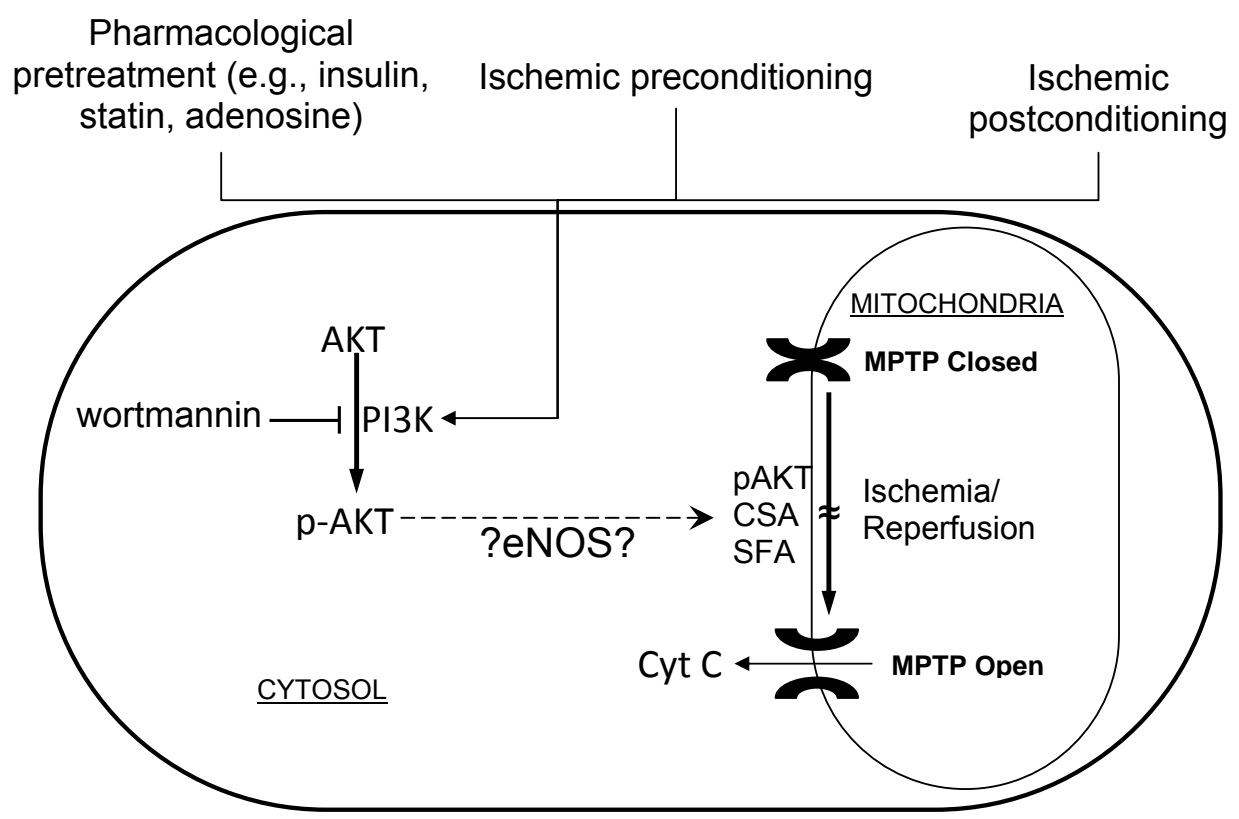

Fig. (3). The reperfusion injury signaling kinase (RISK) pathway. Pharmacological agents, ischemic preconditioning and/or ischemic postconditioning can activate PI3K to precipitate Akt phosphorylation. Akt phosphorylation might prevent opening of the mitochondrial permeability transition pore (MPTP) via endothelial nitric oxide synthase (eNOS). This would be protective because MPTP opening is believed to be an irreversible step toward cell death. CSA, cyclosporine; SFA, sanglifehrin A.

\section{Ischemic PC}

As mentioned earlier, ischemic PC was first described in 1986 as "multiple brief ischemic episodes (that) might actually protect the heart from a subsequent sustained ischemic insult" $[65,66]$. In the landmark paper, myocardial ischemia evoked by occlusion of the circumflex coronary artery for either 40-min or three hours after no treatment (control) or four prior bouts of 5 minutes of ischemia alternating with 5 minutes of reflow (pretreatment). Infarct size evoked by $40-$ min of ischemia was reduced from $30 \%$ to $7 \%$ of the area at risk in control vs. pretreated dogs, respectively; however, infarct size evoked by three hours of ischemia was similar between groups. In 2000, Tong and coworkers demonstrated that inhibition of PI3K, an important component of the RISK pathway, negated the protective effects of preconditioning [155]. Briefly, Langendorff-perfused rat hearts were perfused for 20 minutes (control) or treated with 4 cycles of 5minute ischemia and 5-minute reflow (preconditioning) and then treated with either wortmannin or LY 294002 (PI3K inhibitors) for $5 \mathrm{~min}$ before and throughout PC. The benefits of ischemic PC on left ventricular developed pressure after 30-min of reperfusion were abolished by PI3K inhibition. These data, combined with results showing that ischemic PC resulted in Akt phosphorylation of whole heart homogenates underscores the importance of the PI3K pathway in preconditioning. The importance of MPTP was demonstrated similarly in isolated rat heart subjected to preconditioning $[9,13]$. The beneficial effects of preconditioning could be negated by pretreatment with atractyloside, an MPTP opener. In neonatal rat CMs, the direct relationship between Akt and MPTP has been demonstrated using a combination of western blotting and confocal microscopy.
Table 5. Putative Apoptotic Factors Released at MPTP Opening

\begin{tabular}{|l|l|}
\hline \multicolumn{1}{|c|}{ Effectors of MPTP Opening } & \multicolumn{1}{c|}{ Consequence } \\
\hline \hline Cytochrome C release & $\begin{array}{l}\text { Activation of Caspase 9 which in } \\
\text { turn activates Caspase 3 [144, } \\
146]\end{array}$ \\
\hline Apoptosis Inducing Factor (AIF) & $\begin{array}{l}\text { Translocates to nucleus and } \\
\text { activates DNAses [146] }\end{array}$ \\
\hline $\begin{array}{l}\text { Second mitochondria-derived } \\
\text { activator of Caspase/direct inhibi- } \\
\text { tor of apoptosis binding protein } \\
\text { with a low PI (smac/DIABLO) }\end{array}$ & $\begin{array}{l}\text { Inhibits inhibitors of apoptosis - } \\
\text { in the end proapoptotic [146] }\end{array}$ \\
\hline $\begin{array}{l}\text { Heat Shock Proteins } \\
\text { Ca }{ }^{2+} \text { release }\end{array}$ & $\begin{array}{l}\text { Loss of ability to generate ATP } \\
{[146]}\end{array}$ \\
\hline ROS generation & $\begin{array}{l}\text { Loss of ability to generate ATP } \\
{[146]}\end{array}$ \\
\hline
\end{tabular}

Although the above studies demonstrate that ischemic PC is effective in whole heart preparations, endothelial dysfunction has been specifically demonstrated in experimental models of IR injury [9]. Kharbanda and coworkers examined the effects of forearm ischemia on radial artery flow and demonstrated vasoconstriction in the radial artery after 20 minutes of ischemia, which could be prevented by preconditioning. In addition, the authors reported less neutrophil acti- 
vation in preconditioned human subjects, which they linked to decreased endothelial injury. In another model of human forearm ischemia, infusion of L-arginine (substrate for NO) was protective in response to ischemia [156]. Taken together, these data suggest that preconditioning has a specific endothelial benefit.

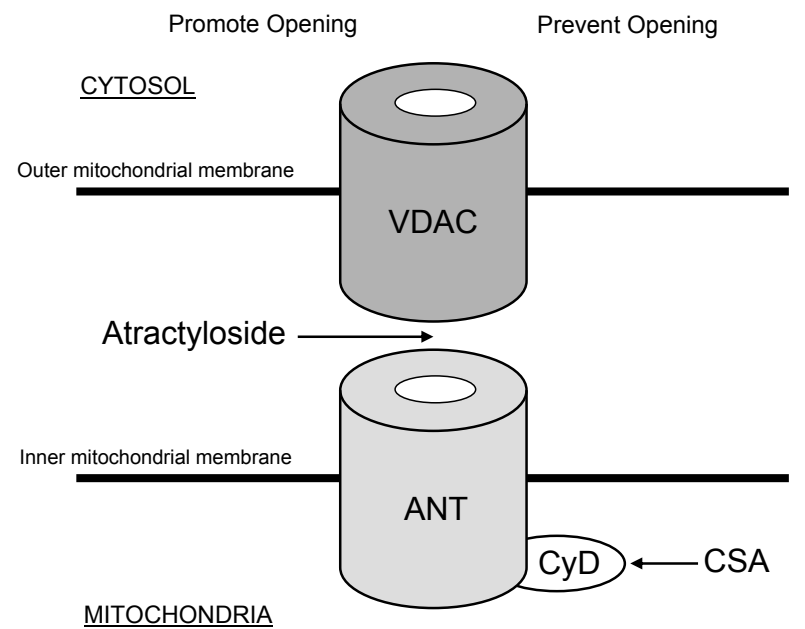

Fig. (4). The mitochondrial permeability transition pore (MPTP) consists of three proteins: adenine nucleotide translocator (ANT); voltage dependent anion conductance (VDAC); and cyclophilin D (CyD). When cyclosporine (CSA) binds to CyD pore opening is prevented and IR injury is limited. Atractyloside is an MPTP opener that exacerbates IR injury.

\section{Postconditioning}

Postconditioning is defined as repetitive bursts of ischemia applied during early reperfusion, which attenuate myocardial reperfusion injury. Postconditioning was originally described in dogs where the left anterior descending artery (LAD) was occluded for 60 minutes and reperfused for three hours [157]. In control dogs there was no intervention, in preconditioned dogs the LAD was occluded for $5 \mathrm{~min}$ and reperfused for $10 \mathrm{~min}$ before the prolonged occlusion, and in postconditioned dogs, at the start of reperfusion, three cycles of 30-s reperfusion and 30-s LAD reocclusion preceded the 3 $\mathrm{h}$ of reperfusion. Both preconditioning $(15 \%, \mathrm{P}=0.05)$ and postconditioning $(14 \%, \mathrm{P}=0.05)$ decreased infarct size compared to controls $(25 \%)$. In addition, neutrophil accumulation and basal endothelial function- assessed by the maximal vasodilator response of post-ischemic LAD to acetylcholine were improved similarly in vessels from preconditioned and postconditioned dogs vs. controls. These observations demonstrate the critical role of the endothelium in preconditioning and postconditioning. Subsequent studies provide evidence for PI3K-Akt activation as a necessary step for the effects of postconditioning to be realized. For example, PI3K inhibitors abolished the benefits of postconditioning [158, 159]. In rabbits, Argaud and coworkers demonstrated that postconditioning, preconditioning and NIM811, a specific inhibitor of the MPTP, reduced MPTP opening and limited infarct size [160]. This study did not specifically detail the effects on endothelium. As with preconditioning, the benefits of postconditioning have been demonstrated in a human forearm model of ischemia by looking at radial artery function in ischemic and postconditioned subjects [161]. Postconditioned subjects had superior preservation of flow relative to untreated subjects. Postconditioning may also work through the induced shear stress in EC, which is known to activate Akt in EC $[90,115]$. Although a direct link between flow and MPTP is not yet established, PI3K-Akt (via the RISK pathway) is mechanosensitive and may be another possible mechanism by which postconditioning is protective. Even though the mechanism is not clearly defined, the endothelium plays a critical role in the protective response induced by postconditioning.

\section{CONCLUSIONS}

Endothelial cells are uniquely situated to modulate IR injury in the heart. They are able to tolerate long periods of ischemia and upon reperfusion activate a variety of blood elements including neutrophils, platelets and complement. Because of their proximity to cardiomyocytes, they can modulate cardiomyocyte function and injury. Further focus on the RISK pathway in EC may present a deeper understanding of IR injury and provide new opportunities for its treatment or prevention.

\section{ACKNOWLEDGEMENTS}

J.D.S. received support from the University of Utah College of Health, University of Utah Research Foundation, American Heart Association (0655222Y), American Diabetes Association (7-08-RA-164), and the National Institutes of Health (HL 091493). Y.E.S. received support from the American Heart Association (0970307N and 0765113Y).

\section{REFERENCES}

[1] Goldberg RJ, Yarzebski J, Lessard D, et al. A two-decades (1975 to 1995) long experience in the incidence, in-hospital and longterm case-fatality rates of acute myocardial infarction: a community-wide perspective. J Am Coll Cardiol 1999; 33: 1533-9.

[2] Rouleau JL, Talajic M, Sussex B, et al. Myocardial infarction patients in the 1990s--their risk factors, stratification and survival in Canada: the Canadian Assessment of Myocardial Infarction (CAMI) Study. J Am Coll Cardiol 1996; 27: 1119-27.

[3] Brutsaert DL. Cardiac endothelial-myocardial signaling: its role in cardiac growth, contractile performance, and rhythmicity. Physiol Rev 2003; 83: 59-115.

[4] Brutsaert DL, Fransen P, Andries LJ, et al. Cardiac endothelium and myocardial function. Cardiovasc Res 1998; 38: 281-90.

[5] Chiba Y, Morioka K, Muraoka R, et al. Effects of depletion of leukocytes and platelets on cardiac dysfunction after cardiopulmonary bypass. Ann Thorac Surg 1998; 65: 107-13.

[6] Davenpeck KL, Gauthier TW, Lefer AM. Inhibition of endothelialderived nitric oxide promotes P-selectin expression and actions in the rat microcirculation. Gastroenterology 1994; 107: 1050-8.

[7] Davidson SM, Duchen MR. Endothelial mitochondria: contributing to vascular function and disease. Circ Res 2007; 100: 1128-41.

[8] Gawaz M. Role of platelets in coronary thrombosis and reperfusion of ischemic myocardium. Cardiovasc Res 2004; 61: 498-511.

[9] Kharbanda RK, Peters $\mathrm{M}$, Walton $\mathrm{B}$, et al. Ischemic preconditioning prevents endothelial injury and systemic neutrophil activation during ischemia-reperfusion in humans in vivo. Circulation 2001; 103: 1624-30.

[10] Frangogiannis NG, Smith CW, Entman ML. The inflammatory response in myocardial infarction. Cardiovasc Res 2002; 53: 31-47.

[11] Kloner RA, Ganote CE, Jennings RB. The "no-reflow" phenomenon after temporary coronary occlusion in the dog. J Clin Invest 1974; 54: 1496-508. 
[12] Crow MT, Mani K, Nam YJ, et al. The mitochondrial death pathway and cardiac myocyte apoptosis. Circ Res 2004; 95: 95770.

[13] Hausenloy DJ, Maddock HL, Baxter GF, et al. Inhibiting mitochondrial permeability transition pore opening: a new paradigm for myocardial preconditioning? Cardiovasc Res 2002; 55: 534-43.

[14] Hausenloy DJ, Yellon DM. New directions for protecting the heart against ischaemia-reperfusion injury: targeting the Reperfusion Injury Salvage Kinase (RISK)-pathway. Cardiovasc Res 2004; 61: 448-60.

[15] Laude K, Beauchamp P, Thuillez C, et al. Endothelial protective effects of preconditioning. Cardiovasc Res 2002; 55: 466-73.

[16] Reffelmann T, Kloner RA. Microvascular alterations after temporary coronary artery occlusion: the no-reflow phenomenon. J Cardiovasc Pharmacol Ther 2004; 9: 163-72.

[17] Reffelmann T, Kloner RA. The "no-reflow" phenomenon: basic science and clinical correlates. Heart 2002; 87: 162-8.

[18] Menger MD, Steiner D, Messmer K. Microvascular ischemiareperfusion injury in striated muscle: significance of "no-reflow". Am J Physiol 1992; 263: H1892-900.

[19] Menger MD, Pelikan S, Steiner D, et al. Microvascular ischemiareperfusion injury in striated muscle: significance of "reflow paradox". Am J Physiol 1992; 263: H1901-6.

[20] Cope JT, Mauney MC, Banks D, et al. Controlled reperfusion of cardiac grafts from non-heart-beating donors. Ann Thorac Surg 1996; 62: 1418-23.

[21] Galinanes M, Qiu Y, Ezrin A, et al. PEG-SOD and myocardial protection. Studies in the blood- and crystalloid-perfused rabbit and rat hearts. Circulation 1992; 86: 672-82

[22] Galinanes M, Ferrari R, Qiu Y, et al. PEG-SOD and myocardial antioxidant status during ischaemia and reperfusion: dose-response studies in the isolated blood perfused rabbit heart. J Mol Cell Cardiol 1992; 24: 1021-30.

[23] Szocs K. Endothelial dysfunction and reactive oxygen species production in ischemia/reperfusion and nitrate tolerance. Gen Physiol Biophys 2004; 23: 265-95.

[24] Vinten-Johansen J, Zhao ZQ, Nakamura M, et al. Nitric oxide and the vascular endothelium in myocardial ischemia-reperfusion injury. Ann N Y Acad Sci 1999; 874: 354-70.

[25] Viehman GE, Ma XL, Lefer DJ, et al. Time course of endothelial dysfunction and myocardial injury during coronary arterial occlusion. Am J Physiol 1991; 261: H874-81.

[26] Tsao PS, Lefer AM. Time course and mechanism of endothelial dysfunction in isolated ischemic- and hypoxic-perfused rat hearts. Am J Physiol 1990; 259: H1660-6.

[27] Tsao PS, Aoki N, Lefer DJ, et al. Time course of endothelial dysfunction and myocardial injury during myocardial ischemia and reperfusion in the cat. Circulation 1990; 82: 1402-12.

[28] Horwitz LD, Kaufman D, Keller MW, et al. Time course of coronary endothelial healing after injury due to ischemia and reperfusion. Circulation 1994; 90: 2439-47.

[29] Iraculis E, Cequier A, Gomez-Hospital JA, et al. Early dysfunction and long-term improvement in endothelium-dependent vasodilation in the infarct-related artery after thrombolysis. J Am Coll Cardiol 2002; 40: 257-65

[30] Quintero M, Colombo SL, Godfrey A, et al. Mitochondria as signaling organelles in the vascular endothelium. Proc Natl Acad Sci USA 2006; 103: 5379-84.

[31] Ricci JE, Waterhouse N, Green DR. Mitochondrial functions during cell death, a complex (I-V) dilemma. Cell Death Differ 2003; 10: 488-92.

[32] Mattson MP, Kroemer G. Mitochondria in cell death: novel targets for neuroprotection and cardioprotection. Trends Mol Med 2003; 9: 196-205

[33] Paravicini TM, Touyz RM. NADPH oxidases, reactive oxygen species, and hypertension: clinical implications and therapeutic possibilities. Diabetes Care 2008; 31 (Suppl 2): S170-80.

[34] Aslan M, Cort A, Yucel I. Oxidative and nitrative stress markers in glaucoma. Free Radic Biol Med 2008; 45: 367-76.

[35] Kurien BT, Scofield RH. Autoimmunity and oxidatively modified autoantigens. Autoimmun Rev 2008; 7: 567-73

[36] Fatokun AA, Stone TW, Smith RA. Oxidative stress in neurodegeneration and available means of protection. Front Biosci 2008; 13: 3288-311.
[37] Nishikawa M. Reactive oxygen species in tumor metastasis. Cancer Lett 2008; 266: 53-9.

[38] Therade-Matharan S, Laemmel E, Duranteau J, et al. Reoxygenation after hypoxia and glucose depletion causes reactive oxygen species production by mitochondria in HUVEC. Am J Physiol Regul Integr Comp Physiol 2004; 287: R1037-43.

[39] Therade-Matharan S, Laemmel E, Carpentier S, et al. Reactive oxygen species production by mitochondria in endothelial cells exposed to reoxygenation after hypoxia and glucose depletion is mediated by ceramide. Am J Physiol Regul Integr Comp Physiol 2005; 289: R1756-62.

[40] Coudray C, Pucheu S, Boucher F, et al. Ischemia and reperfusion injury in isolated rat heart: effect of reperfusion duration on xanthine oxidase, lipid peroxidation, and enzyme antioxidant systems in myocardium. Basic Res Cardiol 1992; 87: 478-88.

[41] Zweier JL, Kuppusamy $\mathrm{P}$, Thompson-Gorman S, et al. Measurement and characterization of free radical generation in reoxygenated human endothelial cells. Am J Physiol 1994; 266: C700-8.

[42] Buttemeyer R, Philipp AW, Mall JW, et al. In vivo measurement of oxygen-derived free radicals during reperfusion injury. Microsurgery 2002; 22: 108-13.

[43] Kim GW, Kondo T, Noshita N, et al. Manganese superoxide dismutase deficiency exacerbates cerebral infarction after focal cerebral ischemia/reperfusion in mice: implications for the production and role of superoxide radicals. Stroke 2002; 33: 80915.

[44] Beaucage P, Massicotte J, Jasmin G, et al. Role of nitric oxide synthase, cytochrome P-450, and cyclooxygenase in the inotropic and lusitropic cardiac response to increased coronary perfusion. $\mathrm{J}$ Cardiovasc Pharmacol 2002; 40: 96-105.

[45] Gaboury JP, Anderson DC, Kubes P. Molecular mechanisms involved in superoxide-induced leukocyte-endothelial cell interactions in vivo. Am J Physiol 1994; 266: H637-42.

[46] Patel KD, Zimmerman GA, Prescott SM, et al. Oxygen radicals induce human endothelial cells to express GMP-140 and bind neutrophils. J Cell Biol 1991; 112: 749-59.

[47] Lucchesi BR. Complement activation, neutrophils, and oxygen radicals in reperfusion injury. Stroke 1993; 24: I41-7.

[48] Schulz R, Kelm M, Heusch G. Nitric oxide in myocardial ischemia/reperfusion injury. Cardiovasc Res 2004; 61: 402-13.

[49] Klimaschewski L, Kummer W, Mayer B, et al. Nitric oxide synthase in cardiac nerve fibers and neurons of rat and guinea pig heart. Circ Res 1992; 71: 1533-7.

[50] Wang P, Zweier JL. Measurement of nitric oxide and peroxynitrite generation in the postischemic heart: evidence for peroxynitritemediated reperfusion injury. J Biol Chem 1996; 271: 29223-30.

[51] Friebe A, Koesling D. Regulation of nitric oxide-sensitive guanylyl cyclase. Circ Res 2003; 93: 96-105.

[52] Grover GJ, Garlid KD. ATP-Sensitive potassium channels: a review of their cardioprotective pharmacology. J Mol Cell Cardiol 2000; 32: 677-95.

[53] Cooke JP. Does ADMA cause endothelial dysfunction? Arterioscler Thromb Vasc Biol 2000; 20: 2032-7.

[54] Bae SW, Stuhlinger MC, Yoo HS, et al. Plasma asymmetric dimethylarginine concentrations in newly diagnosed patients with acute myocardial infaction or unstable angina pectoris during two weeks of medical treatment. Am J Cardiol 2005; 95: 729-33.

[55] Weyrich AS, Ma XL, Lefer AM. The role of L-arginine in ameliorating reperfusion injury after myocardial ischemia in the cat. Circulation 1992; 86: 279-88.

[56] Stuhlinger MC, Conci E, Haubner BJ, et al. Asymmetric dimethyl L-arginine (ADMA) is a critical regulator of myocardial reperfusion injury. Cardiovasc Res 2007; 75: 417-25.

[57] Tanaka M, Sydow K, Gunawan F, et al. Dimethylarginine dimethylaminohydrolase overexpression suppresses graft coronary artery disease. Circulation 2005; 112: 1549-56.

[58] Weis M, Cooke JP. Cardiac allograft vasculopathy and dysregulation of the nitric oxide synthase pathway. Arterioscler Thromb 2003; $23: 567-75$.

[59] Huang PL, Huang Z, Mashimo H, et al. Hypertension in mice lacking the gene for endothelial nitric oxide synthase. Nature 1995 377: 239-42

[60] Sharp BR, Jones SP, Rimmer DM, et al. Differential response to myocardial reperfusion injury in eNOS-deficient mice. Am J Physiol Heart Circ Physiol 2002; 282: 2422-6. 
[61] Shesely EG, Maeda N, Kim HS, et al. Elevated blood pressures in mice lacking endothelial nitric oxide synthase. Proc Natl Acad Sci USA 1996; 93: 13176-81.

[62] Xuan YT, Guo Y, Zhu Y, et al. Endothelial nitric oxide synthase plays an obligatory role in the late phase of ischemic preconditioning by activating the protein kinase $\mathrm{C}$ \{epsilon\}p44/42 mitogen-activated protein kinase-pSer-signal transducers and activators of transcription 1/3 pathway. Circulation 2007; 116: 535-44.

[63] Guo Y, Li Q, Wu WJ, et al. Endothelial nitric oxide synthase is not necessary for the early phase of ischemic preconditioning in the mouse. J Mol Cell Cardiol 2008; 44: 496-501.

[64] Kanno S, Lee PC, Zhang Y, et al. Attenuation of myocardial ischemia/reperfusion injury by superinduction of inducible nitric oxide synthase. Circulation 2000; 101: 2748.

[65] Reimer KA, Murry CE, Yamasawa I, et al. Four brief periods of myocardial ischemia cause no cumulative ATP loss or necrosis. Am J Physiol 1986; 251: H1306-15.

[66] Murry CE, Jennings RB, Reimer KA. Preconditioning with ischemia: a delay of lethal cell injury in ischemic myocardium. Circulation 1986; 74: 1124-36.

[67] Murry CE, Jennings RB, Reimer KA. Preconditioning with ischemia: a delay of lethal cell injury in schemic myocardium. Circulation 1986; 74: 1136

[68] Marber MS, Latchman DS, Walker JM, et al. Cardiac stress protein elevation 24 hours after brief ischemia or heart stress is associated with resistance to myocardial infarction. Circulation 1993; 88: $1264-72$

[69] Bolli R. The late phase of preconditioning. Circ Res 2000; 87: 983

[70] Yellon DM, Downey JM. Preconditioning th myocardium: from cellular physiology to clinical cardiology. Physiol Rev 2003; 83: $1113-51$

[71] Guo Y, Jones WK, Xuan YT, et al. The late phase of ischemic preconditioning is abrogated by targeted disruption of the inducible NO synthase gene. Proc Natl Acad Sci USA 1999; 96: 11507-12.

[72] Ping P, Zhang J, Qiu Y, et al. Ischemic preconditioning induces selective translocation of protein kinase $\mathrm{C}$ isoforms epsilon and eta in the heart of conscious rabbits without subcellular redistribution of total protein kinase C activity. Circ Res 1997; 81: 404-14.

[73] Bolli R, Manchikalapudi S, Tang XL, et al. The protective effect of late preconditioning against myocardial stunning in conscious rabbits is mediated by nitric oxide synthase: evidence that nitric oxide acts both as trigger and as mediator of the late phase of ischemic preconditioning. Circ Res 1997; 81: 1094-107.

[74] Bolli R, Bhatti ZA, Tang XL, et al. Evidence that late precoditioning against myocardial stunning in conscious rabbits is triggered by the generation of nitric oxide. Circ Res 1997; 81: 52 .

[75] Qiu Y, Ping P, Tang XL, et al. Direct evidence that protein kinase $\mathrm{C}$ plays an essential role in the development of late precondtioning against myocardial stunning in conscious rabbits and that epsilon is the isoform involved. J Clin Invest 1998; 101: 2198.

[76] Xuan YT, Tang XL, Banerjee S, et al. Nuclear factor-kappaB plays an essential role in the late phase of ischemic preconditioning in conscious rabbits. Circ Res 1999; 84: 1095-109.

[77] Shinmura K, Tang XL, Wang Y, et al. Cyclooxygenase-2 mediates the cardioprotective effects of the late phase of ischemic preconditioning in conscious rabbits. Proc Natl Acad Sci USA 2000; 97: 10197-10202

[78] Guo Y, Bao W, Wu WJ, et al. Evidence for an essential role of cyclooxygenase-2 as a mediator of late phase of ischemic preconditioning in mice. Basic Res Cardiol 2000; 95: 479-84.

[79] Lefer AM, Whitney CC III, Hock CE. Mechanism of the pressor effect of the calcium agonist, BAY $\mathrm{k}$ 8644, in the intact rat. Pharmacology 1986; 32: 181-9.

[80] Xuan YT, Tang XL, Qiu Y, et al. Biphasic response of cardiac NO synthase isoforms to ischemic preconditioning in conscious rabbits. Am J Physiol Heart Circ Physiol 2000; 279: H2360-71.

[81] Costa AD, Garlid KD, West IC, et al. Protein kinase G transmits the cardioprotective signal from cytosol to mitochondria. Circ Res 2005; 97: 329-36

[82] Qin Q, Yang XM, Cui L, et al. Exogenous NO triggers preconditioning via a cGMP- and mitoKATP-dependent mechanism. Am J Physiol Heart Circ Physiol 2004; 287: H712-8.

[83] Nakano A, Liu GS, Heusch G, et al. Exogenous nitric oxide can trigger a preconditioned state through a free radical mechanism, but endogenous nitric oxide is not a trigger of classical ischemic preconditioning. J Mol Cell Cardiol 2000; 32: 1159-67.

[84] Post H, Schulz R, Behrends M, et al. No involvement of endogenous nitric oxide in classical ischemic preconditioning in swine. J Mol Cell Cardiol 2000; 32: 725-33.

[85] Peters SC, Piper HM. Reoxygenation-induced $\mathrm{Ca}^{2+}$ rise is mediated via $\mathrm{Ca}^{2+}$ influx and $\mathrm{Ca}^{2+}$ release from the endoplasmic reticulum in cardiac endothelial cells. Cardiovasc Res 2007; 73: 164-71.

[86] Fedalen PA, Piacentino V, III, Jeevanandam V, et al. Pharmacologic pre-conditioning and controlled reperfusion prevent ischemia-reperfusion injury after 30 minutes of hypoxia/ischemia in porcine hearts. J Heart Lung Transplant 2003; 22: 1234-44.

[87] Scheule AM, Jost D, Beierlein W, et al. Sodium-hydrogen inhibitor cariporide (HOE 642) improves in situ protection of hearts from non-heart-beating donors. J Heart Lung Transplant 2003; 22: 133542.

[88] Symons JD, Correa SD, Schaefer S. Na-H exchange inhibition with cariporide limits functional impairment caused by repetitive ischemia. J Cardiovasc Pharmacol 1998; 32: 853-62.

[89] Symons JD, Schaefer S. Na+/H+ exchange subtype 1 inhibition reduces endothelial dysfunction in vessels from stunned myocardium. Am J Physiol 2001; 281: H1575-82

[90] Ye Y, Lin Y, Perez-Polo R, et al. Enhanced cardioprotection against ischemia-reperfusion injury with a dipyridamole and lowdose atorvastatin combination. Am J Physiol Heart Circ Physio 2007; 293: H813-8.

[91] Pabla R, Curtis MJ. Endogenous protection against reperfusioninduced ventricular fibrillation: role of neuronal $v s$. non-neuronal sources of nitric oxide and species dependence in the rat $v s$. rabbit isolated heart. J Mol Cell Cardiol 1996; 28: 2097-110.

[92] Trochu JN, Bouhour JB, Kaley G, Hintz TH. Role of endotheliumderived nitric oxide in the regulation of cardiac oxygen metabolism : implications in health and disease. Circ Res 2000; 87: 1108-17.

[93] Zimmer KM and Karmazyn M. Prostaglandins attenuate cardiac contractile dysfunction produced by free radical generation but not by hydrogen peroxide. Mol Cell Biochem 1997; 176: 171-8.

[94] Suzuki YJ. Growth factor signaling for cardioprotection against oxidative stress-induced apoptosis. Antioxid Redox Signal 2003; 6: 741-9.

[95] Vinten-Johansen J. Involvement of neutrophils in the pathogenesis of lethal myocardial reperfusion injury. Cardiovase Res 2004; 61: 481-97.

[96] Thirunavukkarasu M, Juhasz B, Zhan L, et al. VEGFR1 (Flt-1+/-) gene knockout leads to the disruption of VEGF-mediated signaling through the nitric oxide/heme oxygenase pathway in ischemic preconditioned myocardium. Free Radic Biol Med 2007; 42: 1487 95.

[97] von Dobschuetz DE, Meyer S, Thorn D, Marme D, Hopt UT, Thomusch $\mathrm{O}$. Targeting vascular endothelial growth factor pathway offers new possibilities to counteract microvascular disturbances during ischemia/reperfusion of the pancreas. Transplantation 2006; 82: 543-9.

[98] Mohara J, Aguilera I, Goldman BI, et al. Effects of nutrient and hemoglobin enriched cell free perfusates upon ex vivo isolated rat heart preparation. ASAIO J 2005; 51: 288-95.

[99] Di NP, Di CA, Contegiacomo G, et al. Endothelial protective effect of verapamil against acute myocardial contractile dysfunction in isolated working rat hearts subjected to global ischemia. Ann N Y Acad Sci 1998; 853: 311-5.

[100] Weyrich A, Cipollone F, Mezzetti A, et al. Platelets in atherothrombosis: new and evolving roles. Curr Pharm Des 2007; 13: $1685-91$

[101] Weyrich AS, Ma XY, Lefer DJ, et al. In vivo neutralization of Pselectin protects feline heart and endothelium in myocardial ischemia and reperfusion injury. J Clin Invest 1993; 91: 2620-9.

[102] Akers DL, Lefer DJ, Chen IL, et al. Effect of short-term treatment with a monoclonal antibody to P-selectin on balloon catheterinduced: intimal hyperplasia, re-endothelialization, and attenuation of endothelial-dependent relaxation. Mol Cell Biochem 1997; 176: 13-20.

[103] Fukushima S, Coppen SR, Varela-Carver A, et al. A novel strategy for myocardial protection by combined antibody therapy inhibiting both P-selectin and intercellular adhesion molecule-1 via retrograde intracoronary route. Circulation 2006; 114: I251-6.

[104] Ma XL, Lefer DJ, Lefer AM, et al. Coronary endothelial and cardiac protective effects of a monoclonal antibody to intercellular 
adhesion molecule-1 in myocardial ischemia and reperfusion. Circulation 1992; 86: 937-46.

[105] Weisman HF, Bartow T, Leppo MK, et al. Recombinant soluble CR1 suppressed complement activation, inflammation, and necrosis associated with reperfusion of ischemic myocardium. Trans Assoc Am Physicians 1990; 103: 64-72.

[106] Collard CD, Vakeva A, Bukusoglu C, et al. Reoxygenation of hypoxic human umbilical vein endothelial cells activates the classic complement pathway. Circulation 1997; 96: 326-33.

[107] Cowan PJ, Somerville CA, Shinkel TA, et al. High-level endothelial expression of human CD59 prolongs heart function in an ex vivo model of xenograft rejection. Transplantation 1998; 65: 826-831

[108] Davidson SM, Hausenloy D, Duchen MR, et al. Signalling via the reperfusion injury signalling kinase (RISK) pathway links closure of the mitochondrial permeability transition pore to cardioprotection. Int J Biochem Cell Biol 2006; 38: 414-9.

[109] Kim JS, He L, Lemasters JJ. Mitochondrial permeability transition: a common pathway to necrosis and apoptosis. Biochem Biophys Res Commun 2003; 304: 463-70.

[110] Qian T, Nieminen AL, Herman B, et al. Mitochondrial permeability transition in $\mathrm{pH}$-dependent reperfusion injury to rat hepatocytes. Am J Physiol 1997; 273: C1783-92.

[111] Shanmuganathan S, Hausenloy DJ, Duchen MR, et al. Mitochondrial permeability transition pore as a target for cardioprotection in the human heart. Am J Physiol Heart Circ Physiol 2005; 289: H237-42.

[112] Baines CP, Wang L, Cohen MV, et al. Myocardial protection by insulin is dependent on phospatidylinositol 3-kinase but not protein kinase C or KATP channels in the isolated rabbit heart. Basic Res Cardiol 1999; 94: 188-98.

[113] Bell RM, Yellon DM. Atorvastatin, administered at the onset of reperfusion, and independent of lipid lowering, protects the myocardium by up-regulating a pro-survival pathway. J Am Coll Cardiol 2003; 41: 508-15

[114] Kureishi Y, Luo Z, Shiojima I, et al. The HMG-CoA reductase inhibitor simvastatin activates the protein kinase Akt and promotes angiogenesis in normocholesterolemic animals. Nat Med 2000; 6: 1004-10.

[115] Ye C, Bai L, Yan ZQ, et al. Shear stress and vascular smooth muscle cells promote endothelial differentiation of endothelial progenitor cells via activation of Akt. Clin Biomech (Bristol, Avon) 2008; 23 Suppl 1: S118-24.

[116] Zhang Y, Park TS, Gidday JM. Hypoxic preconditioning protects human brain endothelium from ischemic apoptosis by Aktdependent survivin activation. Am J Physiol Heart Circ Physiol 2007; 292: H2573-81.

[117] Zhang QJ, McMillin SL, Tanner JM, et al. Endothelial nitric oxide synthase phosphorylation in treadmill-running mice: role of vascular signalling kinases. J Physiol 2009; 587: 3911-20.

[118] Goh SS, Woodman OL, Pepe S, et al. The red wine antioxidant resveratrol prevents cardiomyocyte injury following ischemiareperfusion via multiple sites and mechanisms. Antioxid Redox Signal 2007; 9: 101-13.

[119] Belke DD, Betuing S, Tuttle MJ, et al. Insulin signaling coordinately regulates cardiac size, metabolism, and contractile protein isoform expression. J Clin Invest 2002; 109: 629-39.

[120] Zeng G, Nystrom FH, Ravichandran LV, et al. Roles for insulin receptor, PI3-kinase, and Akt in insulin-signaling pathways related to production of nitric oxide in human vascular endothelial cells. Circulation 2000; 101: 1539-45.

[121] Muniyappa R, Montagnani M, Koh KK, et al. Cardiovascular actions of insulin. Endocr Rev 2007; 28: 463-91.

[122] Muniyappa R, Quon MJ. Insulin action and insulin resistance in vascular endothelium. Curr Opin Clin Nutr Metab Care 2007; 10: 523-30.

[123] White MF, Kahn CR. The insulin signaling system. J Biol Chem 1994; 269: 1-4.

[124] Jialal I, Crettaz M, Hachiya HL, et al. Characterization of the receptors for insulin and the insulin-like growth factors on microand macrovascular tissues. Endocrinology 1985; 117: 1222-9.

[125] Symons JD, McMillin SL, Riehle C, et al. Contribution of insulin and Akt1 signaling to eNOS in the regulation of endothelial function and blood pressure. Circ Res 2009; 104: 1085-94.

[126] Hermann C, Assmus B, Urbich C, et al. Insulin-mediated stimulation of protein kinase Akt: A potent survival signaling cascade for endothelial cells. Arterioscler Thromb Vasc Biol 2000; 20: 402-9.

[127] Kuboki K, Jiang ZY, Takahara N, et al. Regulation of endothelial constitutive nitric oxide synthase gene expression in endothelial cells and in vivo. Circulation 2000; 101: 676-81.

[128] Etgen GJ, Jr, Fryburg DA, Gibbs EM. Nitric oxide stimulates skeletal muscle glucose transport through a calcium/contractionand phosphatidylinositol-3-kinase-independent pathway. Diabetes 1997; 46: 1915-19.

[129] Young ME, Radda GK, Leighton B. Nitric oxide stimulates glucose transport and metabolism in rat skeletal muscle in vitro. Biochem $\mathrm{J}$ 1997; 322 ( Pt 1): 223-8.

[130] Beauloye C, Bertrand L, Krause U, et al. No-flow ischemia inhibits insulin signaling in heart by decreasing intracellular $\mathrm{pH}$. Circ Res 2001; 88: 513-9.

[131] Fujio Y, Nguyen T, Wencker D, et al. Akt promotes survival of cardiomyocytes in vitro and protects against ischemia-reperfusion injury in mouse heart. Circulation 2000; 101: 660-7.

[132] Jonassen AK, Sack MN, Mjos OD, et al. Myocardial protection by insulin at reperfusion requires early administration and is mediated via Akt and p70s6 kinase cell-survival signaling. Circ Res 2001; 89: 1191-8.

[133] Matsui T, Tao J, del MF, et al. Akt activation preserves cardiac function and prevents injury after transient cardiac ischemia in vivo. Circulation 2001; 104: 330-5.

[134] Nagoshi $\mathrm{T}$, Matsui $\mathrm{T}$, Aoyama $\mathrm{T}$, et al. PI3K rescues the detrimental effects of chronic Akt activation in the heart during ischemia/reperfusion injury. J Clin Invest 2005; 115: 2128-38.

[135] Budas GR, Sukhodub A, Alessi DR, et al. 3'Phosphoinositidedependent kinase- 1 is essential for ischemic preconditioning of the myocardium. FASEB J 2006; 20: 2556-8.

[136] Crompton M. The mitochondrial permeability transition pore and its role in cell death. Biochem J 1999; 341 ( Pt 2): 233-49.

[137] Halestrap AP, Brennerb C. The adenine nucleotide translocase: a central component of the mitochondrial permeability transition pore and key player in cell death. Curr Med Chem 2003; 10: 150725 .

[138] Javadov SA, Clarke S, Das M, et al. Ischaemic preconditioning inhibits opening of mitochondrial permeability transition pores in the reperfused rat heart. J Physiol 2003; 549: 513-24.

[139] Green DR, Reed JC. Mitochondria and apoptosis. Science 1998; 281: 1309-12.

[140] Griffiths EJ, Halestrap AP. Protection by Cyclosporin A of ischemia/reperfusion-induced damage in isolated rat hearts. $\mathrm{J}$ Mol Cell Cardiol 1993; 25: 1461-9.

[141] Schneider MD. Cyclophilin D: knocking on death's door. Sci STKE 2005; 2005: e26.

[142] Baines CP, Kaiser RA, Purcell NH, et al. Loss of cyclophilin D reveals a critical role for mitochondrial permeability transition in cell death. Nature 2005; 434: 658-62.

[143] Crompton M, Ellinger H, Costi A. Inhibition by cyclosporin A of a $\mathrm{Ca}^{2+}$-dependent pore in heart mitochondria activated by inorganic phosphate and oxidative stress. Biochem J 1988; 255: 357-60.

[144] Crompton M, Costi A, Hayat L. Evidence for the presence of a reversible $\mathrm{Ca}^{2+}$-dependent pore activated by oxidative stress in heart mitochondria. Biochem J 1987; 245: 915-8.

[145] Kroemer G, Galluzzi L, Brenner C. Mitochondrial membrane permeabilization in cell death. Physiol Rev 2007; 87: 99-163.

[146] Kroemer G, Galluzzi L, Brenner C. Mitochondrial Membrane Permeabilization in Cell Death. Physiol Rev 2007; 87: 99-163.

[147] Walter DH, Haendeler J, Galle J, et al. Cyclosporin A inhibits apoptosis of human endothelial cells by preventing release of cytochrome $\mathrm{C}$ from mitochondria. Circulation 1998; 98: 1153-7.

[148] Raymond MA, Mollica L, Vigneault N, et al. Blockade of the apoptotic machinery by cyclosporin A redirects cell death toward necrosis in arterial endothelial cells: regulation by reactive oxygen species and cathepsin D. FASEB J 2003; 17: 515-7.

[149] Dustan HP. Mechanisms of hypertension associated with obesity. Intern Med 1983; 98: 860-4.

[150] Robb-Nicholson C, Currie WD, Wechsler AS. Effects of verapamil on myocardial tolerance to ischemic arrest: comparison to potassium arrest. Circulation 1978; 58: I119-24.

[151] Yang XM, Krieg T, Cui L, et al. NECA and bradykinin at reperfusion reduce infarction in rabbit hearts by signaling through PI3K, ERK, and NO. J Mol Cell Cardiol 2004; 36: 411-21. 
[152] Diaz R, Paolasso EA, Piegas LS, et al. Metabolic modulation of acute myocardial infarction. The ECLA (Estudios Cardiologicos Latinoamerica) Collaborative Group. Circulation 1998; 98: 222734.

[153] Bothe W, Olschewski M, Beyersdorf F, et al. Glucose-insulinpotassium in cardiac surgery: a meta-analysis. Ann Thorac Surg 2004; 78: 1650-7.

[154] Alvarez-Arroyo MV, Yague S, Wenger RM, et al. Cyclophilinmediated pathways in the effect of cyclosporin A on endothelial cells: role of vascular endothelial growth factor. Circ Res 2002; 91 : 202-9.

[155] Tong H, Chen W, Steenbergen C, et al. Ischemic preconditioning activates phosphatidylinositol-3-kinase upstream of protein kinase C. Circ Res 2000; 87: 309-15.

[156] Pernow J, Bohm F, Beltran E, et al. L-arginine protects from ischemia-reperfusion-induced endothelial dysfunction in humans in vivo. J Appl Physiol 2003; 95: 2218-22.
[157] Zhao ZQ, Corvera JS, Halkos ME, et al. Inhibition of myocardial injury by ischemic postconditioning during reperfusion: comparison with ischemic preconditioning. Am J Physiol Heart Circ Physiol 2003; 285: H579-88.

[158] Sivaraman V, Mudalagiri NR, Di SC, et al. Postconditioning protects human atrial muscle through the activation of the RISK pathway. Basic Res Cardiol 2007; 102: 453-9.

[159] Zhu M, Feng J, Lucchinetti E, et al. Ischemic postconditioning protects remodeled myocardium via the PI3K-PKB/Akt reperfusion injury salvage kinase pathway. Cardiovase Res 2006; 72: 152-62.

[160] Argaud L, Gateau-Roesch O, Raisky O, et al. Postconditioning inhibits mitochondrial permeability transition. Circulation 2005; 111: 194-7.

[161] Loukogeorgakis SP, Panagiotidou AT, Yellon DM, et al. Postconditioning protects against endothelial ischemia-reperfusion injury in the human forearm. Circulation 2006; 113: 1015-9.

Received: July 21, 2009

Revised: August 22, 2009

Accepted: December 30, 2009

(C) Singhal et al.; Licensee Bentham Open.

This is an open access article licensed under the terms of the Creative Commons Attribution Non-Commercial License (http://creativecommons.org/licenses/by$\mathrm{nc} / 3.0 /$ ) which permits unrestricted, non-commercial use, distribution and reproduction in any medium, provided the work is properly cited. 